\title{
Feasibility of Meeting Increased Biofuel Mandates with E85
}

\author{
Sébastien Pouliot ${ }^{*}$ and Bruce A. Babcock
}

\begin{abstract}
The Environmental Protection Agency implements the Renewable Fuel Standard through annual blending mandates for different categories of biofuels. In its proposed rule released for the 2014, 2015 and 2016 calendar years, EPA reduced mandates because the volume of ethanol that consumers can easily use is lower than the original mandates specified in the Renewable Fuels Standard. This study estimates the demand for E85 using a new dataset that allows direct inference about the demand from the data. We report on how owners of flex vehicles in two metropolitan areas responded to changes in the price of E85. Using our new estimates of consumer demand, we find that owners of current flex vehicles in all US metro areas would consume 285 million gallons of E85 if it was priced at parity on a cost-per-mile basis with E10, and one billion gallons of E85 if it was priced to save drivers $20 \%$ on a costper-mile basis.
\end{abstract}

Keywords: Biofuel, Ethanol, Flex Fuel Vehicles, Gasoline, Mandate.

JEL codes: Q18, Q41, Q42.

Author information and acknowledgements: Sébastien Pouliot is an associate professor in the Department of Economics at lowa State University and a member of the Center for Agricultural and Rural Development. Bruce A. Babcock is a professor and Cargill Chair in Energy Economics in the Department of Economics at lowa State University. The authors acknowledge support from the Biobased Industry Center at lowa State University and the National Science Foundation under Grant Number EPS1101284.

\footnotetext{
* Corresponding author. Department of Economics, lowa State University. 260 Heady Hall, Ames IA 50010. Email: pouliot@iastate.edu.
} 


\section{Introduction}

The U.S. Renewable Fuel Standard (RFS) requires the Environmental Protection Agency (EPA) to specify annual blending mandates for different categories of biofuels. EPA issues overall mandates for renewable fuel and advanced biofuels as well as specific mandates for cellulosic biofuel and biomassbased diesel. The difference between the renewable fuel mandate and the advanced biofuel mandate can be met with corn ethanol so it is commonly known as the corn ethanol mandate, although it can be met with any qualifying biofuel. The 2016 corn ethanol mandate is 14.5 billion gallons. EPA has proposed to increase this mandate to 14.8 billion gallons in 2017. The US Energy Information Agency (EIA) currently estimates that US consumption of motor gasoline will be approximately 143 billion gallons in both n 2016 and 2017 (EIA 2016). EIA estimates that 99\% of U.S. gasoline contains 10\% ethanol (E10), which implies that 14.2 billion gallons of ethanol will be consumed in E10. Simple arithmetic demonstrates that if the corn ethanol mandate is going to be met with ethanol, then 400 and 600 million gallons of ethanol must be consumed in blends containing more than $10 \%$ ethanol in 2016 and 2017 respectively.

The two approved U.S. blends that contain more than $10 \%$ ethanol are E15 and E85. The number of stations that sell E15 is currently quite small, whereas about 2,800 stations currently sell E85. Thus, sales of E85 must be high enough to meet the corn ethanol mandate in 2016 and 2017. EPA (2015a) was explicit about their expectation writing in its 2015 proposed rule about E85: "Thus we believe it is possible for the market to reach volumes perhaps as high as 600 million gallons under favorable pricing conditions" (p. 33, 127). If the 2016 and proposed 2017 mandates are to be met with a combination of $\mathrm{E} 10$ and $\mathrm{E} 85$, then between 400 and 800 million gallons of E85 must be consumed. ${ }^{\dagger}$

Only motorists who drive flex fuel vehicles (FFVs) should fuel their car with E85. Cost-minimizing drivers with easy access to E85 should choose E85 when the cost per mile of driving with it is lower than

\footnotetext{
${ }^{\dagger}$ Throughout this paper, we fix the ethanol content of E85 at 75\%, although it can contain anywhere from $51 \%$ to $83 \%$ ethanol.
} 
with E10. Accounting for the lower energy content of ethanol, this occurs when the pump price of E85 is 22\% lower than E10.

The RFS compliance mechanism uses Renewable Identification Numbers (RINs) in a tradable permit program to lower the price of biofuels enough to induce mandated consumption levels. Pouliot and Babcock (2016) explain in detail how the ethanol RIN market works for conventional ethanol. A RIN is generated with every gallon of ethanol produced. After the gallon is blended with gasoline, its RIN is detached and sold (or simply transferred in the case of vertically integrated blenders) to refineries to show compliance with mandates. The market price of RINs is endogenous to the mandated volume: the more difficult it is to consume a given volume of ethanol, the higher the price of RINs.

The RIN price is effectively a tax on wholesale gasoline that subsidizes wholesale ethanol, thus the RIN price reflects the marginal compliance cost of the RFS. The wholesale price of ethanol is typically quoted inclusive of the RIN. Thus, in a competitive market, a higher RIN price means a lower net cost of ethanol going into retail fuel but a higher cost for gasoline going into retail fuel thereby decreasing the cost of producing E85 relative to E10 (Whistance, Thompson and Westoff 2014).

To better explain why a high RIN price can make E85 attractively priced, suppose that the wholesale price of ethanol at a blending station is $\$ 1.40$ per gallon and the RIN price is $\$ 0.65$ per gallon. The blender pays $\$ 1.40$ for the ethanol and the attached RIN. To break even on the transaction, the blender can sell the RIN for $\$ 0.65$ and price the ethanol in the blended fuel at $\$ 0.75$ per gallon. If the gasoline in the blended fuel costs $\$ 1.35$, the blender can create E85 (75\% ethanol and $25 \%$ gasoline) at a break-even cost of $\$ 0.90$ per gallon, and E10 at a break-even cost of $\$ 1.29$. Assuming a \$0.75 per gallon retail-to-wholesale markup including federal and state gasoline taxes (Pouliot and Babcock 2014), the retail price of E10 is $\$ 2.04$ per gallon and the retail price of E85 is $\$ 1.65$ per gallon, resulting in a $19 \%$ discount on the price of E10. If the RIN price increases to $\$ 0.85$ per gallon because of an increase in the ethanol mandate and everything else remains constant, then 
the break-even price of E85 at retail is $\$ 1.50$ per gallon and the price of E10 at retail is $\$ 2.02$ per gallon, making the price of E85 26\% lower. ${ }^{\ddagger}$ Thus, a higher RIN price makes it possible to price E85 at levels that are attractive to consumers.

The most important factor determining the level of compliance costs associated with a given level of the ethanol mandate is the RIN price required to lower the relative price of E85 enough to induce consumers to buy enough of it to meet the mandate. EPA has found it difficult to set mandate levels that balance consideration of compliance costs with meeting the ethanol blending targets of the RFS. The gap between the renewable fuel mandate and the advanced biofuel mandate in the RFS legislation was scheduled to rise to its maximum level of 15 billion gallons in 2015 , which would have required consumption of 1.47 billion gallons of E85 to meet. ${ }^{\S}$ EPA decreased mandates in 2014, 2015 and 2016 because it determined that consumers would not buy enough E85 to achieve a 15-billiongallon mandate even if RIN prices increase enough to drive the blender cost of ethanol to zero. The reason why EPA made this determination was a combination of too few retail outlets that sold E85 and too few FFVs in areas that did sell the fuel.

Because the demand for E85 is key to determining the cost and feasibility of meeting blending targets, much effort has been targeted at its estimation. Models of consumer switching behavior between E85 and E10 include work by Anderson (2012), Liu and Greene (2014), de Gorter and Drabik (2015) and Pouliot and Babcock (2016). Drabik, et al. (2015) use Brazilian data and a logistic curve to model fuel switching decisions. de Gorter and Drabik (2015) adopt a similar approach to modeling the choice of E85 versus E10 in the United States. The parameters of the logistic function are calibrated using previous E85 demand points from the literature. Pouliot and Babcock (2014)

\footnotetext{
${ }^{\ddagger}$ The increase in the price of RIN would cause a slight increase in the price of gasoline because the RIN is effectively a tax on gasoline. With an increase in the price of RIN of $\$ 0.20$ per gallon and an ethanol blending mandate of $10 \%$, the price of gasoline increases by $\$ 0.02$ per gallon. We ignore this small increase in these calculations.

$\S$ Gasoline consumption in 2015 was 140.7 billion gallons, which implies consumption of ethanol in E10 was 13.9 billion gallons $(140.7 * 0.99 * 0.10)$, thereby requiring 1.1 billion gallons of ethanol or 1.47 billion gallons of E85.
} 
derive a demand function for E85 in the United States that captures the distribution of preferences over E10 versus E85 as well as the cost associated with finding the nearest gas station selling E85. One weakness of their approach was that they calibrated the distribution of preferences of U.S. consumers for E85 relative to E10 using estimates from Brazil. Pouliot and Babcock (2014) estimate that 800 million gallons of ethanol could be consumed nationwide as E85 with a cap of around one billion gallons as the blender cost of ethanol approaches zero.

Our contribution here is to use a unique dataset to provide improved estimates of FFV owners' willingness to buy E85, and to use the willingness-to-pay estimates to obtain more accurate estimates of the tradeoff between ethanol consumption levels and marginal compliance costs. Given the focus on ethanol in meeting RFS blending mandates, we focus on compliance with the RFS mandate from an increase in the consumption of ethanol that is endogenously brought by an increase in the price of RINs for conventional ethanol. Our results provide more relevant estimates of the tradeoff between mandate levels and marginal compliance costs than provided by Pouliot and Babcock (2014), because they are based on daily retail prices and fuel sales obtained from the owner of a major U.S. chain of retail gasoline outlets. The data cover all sales from that fuel retailer between 2011 and 2014. During this period the price of E85 relative to E10 has varied dramatically, allowing us to trace out how consumption of E85 varies with its price. Here we report on how owners of FFVs in two metropolitan areas responded to changes in the price of E85. Perhaps uniquely, this chain's aggregate market share in the metro area was much greater than $90 \%$, thus allowing us to estimate the proportion of owners of FFVs in the area who chose to switch from E10 to E85 at various prices. ${ }^{* *}$ Extrapolating these new direct estimates of consumer demand to all metro areas, we calculate that current owners of flex vehicles in all US metro areas would consume 285 million gallons

\footnotetext{
** To obtain access to the data we needed to sign a non-disclosure agreement whereby we agreed not to identify the company that generated the data. We cannot identify the two metro areas because if we did, then that would reveal the identity of the retailer.
} 
of E85 if it is priced at parity on a cost per mile basis with E10, and 1 billion gallons of E85 if it is priced to save drivers $20 \%$ on a cost per mile basis. These estimates assume that no new E85 stations are installed. If 5,000 new stations are installed, then between 675 million and 1.2 billion gallons of E85 would be consumed in E85 in US metro areas if E85 were priced at parity with E10. The consumption level depends on whether the new fuel stations are strategically located. We provide consumption estimates if fewer than 5,000 stations actually get installed. These estimates understate total US E85 consumption because consumption in non-metro areas is not included.

\section{Model of the demand for E85}

The demand for E85 depends on three factors: 1) infrastructure to dispense E85; 2) the size of the FFV fleet; and 3) motorists' willingness to pay for E85 relative to E10. Below we describe each of these factors and how they affect the total consumption of E85. We then show how these factors can be combined into a single equation as in Pouliot and Babcock (2014) to model the aggregate demand for E85 and discuss the limitations of inference based on such a calibrated equation.

\subsection{E85 fuel stations}

A limited number of fuel stations offer E85. The 2013 County Business Patterns annual series reports that there are about 112,500 fuel stations in the United States (US Census Bureau, 2015). Out of those, about 2,800 public fuel stations offer E85 (Alternative Fuels Data Center 2016). The scarcity of fuel stations carrying E85 is a major obstacle for the expansion of the consumption of ethanol through E85. Several states (mainly in the Midwest) have provided financial incentives for the installation of E85 pumps. More recently, USDA announced that 21 states will receive funds for the installation of 5,000 pumps offering higher blends of ethanol (USDA 2015). 
Data from Alternative Fuels Data Center (2016) show that the largest concentration of E85 pumps is in the Corn Belt where most of the ethanol is produced but where population density is relatively low. Many large population centers are served by just a few E85 pumps. The limited distribution of E85 is a significant constraint in the expansion of E85 consumption as most motorists do not have access to an E85 pump on their regular commute (Pouliot and Babcock 2014).

\subsection{Flex fuel vehicles fleet}

Most cars in the United States were designed to run on fuel blends that contain no more than $10 \%$ ethanol. FFVs can run on any gasoline-ethanol blend. In the early years of the RFS, government fleets adopted FFVs to provide an incentive for the installation of E85 pumps (Corts 2010). Car makers have incentives to sell FFVs because they receive additional fuel efficiency credits to help them meet the Corporate Average Fuel Economy (CAFE) standards (Anderson and Sallee 2011).

Potential regional demand for E85 is determined by the number of FFVs owned in the region. Pouliot and Babcock (2014), with a dataset that details the location of FFVs in the United States, find that there were about 14.6 million registered FFVs in the United States at the beginning of 2013. We purchased data from Hedges and Company that report ownership of FFVs by US zip code for the entire United States as of January 1, 2015. This is an update on the data in Pouliot and Babcock (2014). This dataset shows that 18 million FFVs were registered in the United States. Pouliot and Babcock (2014) observe that increasing the number of FFVs has a small impact on the consumption of E85 because the number of fuel stations offering E85 is a much more important consumption constraint.

\subsection{Relative price of $\mathrm{E} 10$ and $\mathrm{E} 85$}

For a flex motorist with easy access to an E85 pump, an important factor that will determine whether to consume E85 is its price relative to E10. Ethanol contains about 2/3rds of the energy content of gasoline. 
This means that E85 with $75 \%$ ethanol has about $22 \%$ less energy than E10. Motorists may discount E85 relative to E10 even more than $22 \%$ because the lower energy content means more frequent fueling. Some motorists might be willing to pay a premium for E85 because they believe it is better for the environment or because they wish to support farmers. Therefore, there is a distribution of willingness to pay for E85 relative to E10 that should be centered near the price ratio where the cost-per-mile driven is about equal between the two fuels.

Using consumption data for Minnesota, Anderson (2012) finds that a $\$ 0.10 /$ gal increase in E85's price relative to E10 leads to a $12 \%-16 \%$ decrease in the consumption of E85. However, Anderson (2012) is not able to estimate a full distribution of willingness to pay for E85 because in his data E85 was priced at a premium over E10. It was not until 2013 that a significant discount for E85 was observed. Petrolia et al. 2010 and Aguilar et al. (2015) overcome the problem with limited observation of a discount on E85 by respectively using contingent valuation and a discrete choice experiment. Both studies provide evidence that a significant share of motorists are willing to pay a premium for E85. Neither study however uses actual transaction data to make their estimates.

The green line in Figure 1 shows the ratio of a calculated wholesale price of E85 to a calculated wholesale price of E10 based on observed futures prices for gasoline and ethanol and on the price of RINs. From March of 2013 to the end of data plotted, the RIN-adjusted price of E85 was usually low enough to make the cost per mile of running an FFV on E85 lower than on E10. But this "theoretical" wholesale price of E85 will not reflect the actual price that consumers pay unless there is sufficient competition between oil companies, between gasoline blenders, and between retailers to ensure that RIN prices are fully reflected in the price that consumers pay at the pump. Empirically, Knittel, Meiselman, and Stock (2015) find that the one-day pass-through of the change in RIN price on a change in the wholesale price of ethanol is roughly $50 \%$ to $75 \%$ but the long-run pass-through is $100 \%$. However, Knittel, Meiselman, and Stock (2015) estimate that the pass-through of the RIN price on the 
E10-E85 spread at the retail level is zero. The imperfect RIN pass-through at the retail level is another obstacle in the expansion of E85 sales.

\subsection{Aggregate demand for E85}

Similar to Pouliot and Babcock (2014), we can write the total demand for E85 as

$$
Q_{85}=N_{f} \int_{0}^{d_{\max }} q_{85}\left(p_{85}(x)\right)\left(1-H\left(\frac{p_{85}(x)}{p_{10}}\right)\right) g(x) d x
$$

where $N_{f}$ is total number of FFVs, $p_{85}$ is the price of E85, $p_{10}$ is the price of E10, $q_{85}$ is consumption of E85 as a function of the price of E85, $H$ is the cumulative distribution of willingness to pay for E85 versus E10, and $g$ is the marginal distribution of the distance between flex motorists and an E85 pump.

The total price paid for E85 by a flex motorist is the sum of the retail E85 price and the driving cost to access an E85 pump. Thus, the total price paid by consumers for E85 is an increasing function of the distance to drive to access an E85 pump, which is scarcely distributed compared to widely available E10 for which driving cost is normalized to zero. The marginal distribution function $g$ describes the distance that motorists must drive to access E85 pumps. Integrating over all distances between 0 and $d_{\max }$, which can be as much as a few hundred miles, covers all flex motorists. An increase in the number of stations offering E85 modifies the distribution function $g$ such that the new distribution function $g_{1}$ stochastically dominates the old distribution function $g_{0}$.

A motorist who must drive a distance $d$ to access an E85 pumps makes the decision to either purchase E85 at a total price $p_{85}(d)$ or E10 at a price $p_{10}$. In aggregate, the willingness to pay for E85 versus $\mathrm{E} 10$ is summarized by the distribution function $H$, which is a function of willingness to pay for

E85. Thus, $1-H\left(\frac{p_{85}(d)}{p_{10}}\right)$ is the share of motorists who purchase E85 given a distance $d$. The 
quantity demanded of E85 by a motorist is a decreasing function of the price of E85. Multiplying the consumption by a motorist and the propensity of fuel with E85 yields the expected consumption for a motorist who has to drive a distance $d$ to access E85. Integrating over the range of distances yields the expected E85 consumption per flex motorist. Then multiplying by the number of FFVs yields the total consumption of E85 in equation (1).

Equation (1) shows how the three factors discussed above combine to determine the demand for E85. Pouliot and Babcock (2014) calibrate an equation similar to the demand in (1) to derive the total demand for E85. They rely on estimates from the literature to calibrate the distribution function for the willingness to pay for E85 and make educated guesses regarding the cost of access to E85 pumps. Below, we use a new dataset that allows us to estimate together the propensity to purchase E85 and the driving cost to access an E85 pump. Thus, we can measure the proportion of flex motorists who purchase E85 given observed E85 and E10 prices without relying on assumptions on the cost of accessing an E85 pump.

\section{Methodology}

We obtained access to proprietary data from a fuel retailer that sold E85 mostly in the Midwest. We use sales data between January 2011 and December 2014 for two metro areas where the fuel retailer essentially has a monopoly in the sale of E85. Furthermore, the retailer charged a uniform price for E85 at all the stations within the metro area. Thus, we have weekly data that shows the response of virtually all drivers of FFVs in two metro areas to a range of relative prices for E10 and E85.

The discussion in the previous section shows that the variables that explain the consumption of E85 are the number of FFVs, the distance to an E85 pump, and the prices of E85 and E10. Our approach is to model the E85 consumption share among flex motorists as a function of an intercept, the E85-E10 
price ratio $\left(p_{85} / p_{10}\right)$, the number of E85 fuel stations per square mile, and a dummy variable for the second metro area:

$$
s_{85 t i}=b_{0}+b_{1}(\text { price ratio })_{t i}+b_{2}(\text { station per square mile })_{t i}+b_{3}(\text { metro area } 2)_{t i}+u_{i t},
$$

where $t$ denotes time and $i$ identifies the metropolitan area. The variables for consumption share, the price ratio, and the number of stations per square mile will be measured either in level or in log depending on the regression model.

If the price ratio is low, not only flex motorists who are regular consumers at a fuel station offering E85 will switch to E85-other flex motorists might go out of their way to fuel with E85. The number of E85 stations per square mile captures the ease of access to E85. The greater the number of E85 fuel stations per square mile, the easier the access to E85, such that we expect an increase in the consumption share with the number of fuel stations per square mile. Together, the coefficients for the price ratio and the number of stations per square mile summarize the average motorists' preference for E85 and the average cost of access to an E85 pump among flex motorists in a metro area. We include a dummy variable for metro area 2 to test whether there is something specifically different between metro areas 1 and 2 other than the price ratio and the number of stations per square mile that explains preferences or access costs.

The triangles and dots in Figure 1 show the average weekly price ratio of E85 to the price of E10 for the two regions. The large variation in the price ratio at the pump during this time is what is needed to estimate how owners of FFVs respond to E85 price changes. Observe that that the price of E85 in metro area 2 has been much less favorable to the consumption of E85. This reflects regional differences in the ability of the retailer to access low-cost E85. Except for a few weeks in 2014, the retail prices for E85 have been higher than the theoretical wholesale price calculated based on futures price data. 
Because the retailer has a monopoly in the sale of E85 in the two metro areas, the data provide us with the total consumption of E85 by flex motorists in the two metro areas. ${ }^{+\dagger}$ However, consumption of E10 by flex motorists is not observable. To calculate flex motorists' E10 consumption, we take the number of FFVs multiplied by their expected consumption given the observed price for E10. We find how many FFVs are driven in our two metro areas by identifying all the zip codes in the metro areas and then adding up all the FFVs in each of the zip codes. We use the number of FFVs per zip code for January 2013 from Pouliot and Babcock (2014) and our new dataset with the same data for January 2015. We extrapolate linearly between the two observations to find the number of FFVs per zip code for every week between January 2011 and December 2014. Of course, some of these FFVs will fill up outside the metro area and FFVs from outside the area will fill up inside the metro area. We have no data that allows us to control for these movements so we simply assume that they cancel each other out.

The next step is to estimate the expected consumption of E10 by individual flex motorists. FFVs are generally light trucks and larger SUVs because car manufacturers could benefit from the US Corporate Average Fuel Economy (CAFE) standards for producing FFVs and these credits were more valuable on larger vehicles (Anderson and Sallee 2011). Alternative Fuels Data Center (2015b) shows that, on average, light trucks consume 683 gallons of gasoline (E0) per year. This is equivalent to an E10 consumption of 707 gallons or an average weekly consumption of 13.59 gallons. With an average gasoline price of $\$ 2.43 /$ gal for 2015 (EAI 2015a), and assuming a demand elasticity of - 0.25 (Lin and Prince 2013), we calibrate the weekly consumption of E10 by a flex motorist who fuels with E10 as $q_{g}=16.96 p_{g}^{-0.25}$ where $q_{g}$ is the quantity of E10 and $p_{g}$ is the price of E10. By dividing $q_{g}$ by 0.776 , the relative energy content of E85 compared to E10, we can find the quantity of E85 that yields the same number of miles as the quantity of E10 that would be consumed by the FFVs given the observed

\footnotetext{
${ }^{++}$There is one other station in metro area 1 that sells E85. However, that station is small and sells limited volumes of E85. We believe that ignoring that station is inconsequential to our results.
} 
price for E10. With the demand for E10, we can then estimate market penetration by dividing the observed level of E85 consumption by the predicted total gasoline consumption by flex motorists measured in E85 energy equivalent volume.

Figure 2 shows the calculated weekly E85 consumption share between 2011 and 2014. The effect of lower prices on E85 consumption is apparent in the data but appears different in metro areas 1 and 2. In metro area 1, for each 5 percentage point drop in the relative price of E85, market penetration increases by approximately $2.5 \%$. When the relative price drops below parity, however, the consumption share appears to become more responsive to relative price. A greater response makes sense because once E85 is priced low enough to save drivers money, E85 will catch the attention of owners of FFVs who might not normally consider filling up with E85. In metro area 2, the price ratios observed are all above cost-per-mile parity. However, it is still apparent that lower E85 prices cause an increase in the consumption share of E85. The number of fuel stations offering E85 in metro area 2 is lower than in metro area 1, explaining the lower consumption share. An increase in the number of fuel stations offering E85 in metro area 2 explains why there are two distinct consumption shares for a price ratio of 0.8 . The increase in the number of E85 pumps lowered the cost of accessing E85 and thus increased consumption of E85.

Our data on fuel sales contain the location of E85 fuels stations. We identified the zip codes that define the two metro areas. Using data from US Census Bureau (2014) for the land area per zip code, we calculate the concentration of E85 fuels station per square mile for the two metro areas. In metro area 1, the number of E85 stations per square mile went from 0.038 in January 2011 to 0.063 in December 2014. In metro area 2, the number of E85 fuel stations per square mile between January 2011 and December 2014 increased from 0.006 to 0.022 . 
Unit roots tests show evidence that the variables of the model have unit roots. ${ }^{\ddagger \ddagger}$ Given the unit roots, we will look for cointegration as indicated by stationary regression residuals. We use the PhillipsOuliaris test under the null-hypothesis that the variables of the model are not cointegrated. With the rejection of a unit-root in the residuals we conclude the existence of cointegration. Table 1 summarizes the regression outcomes for six specifications. Models 1 and 2 are linear in logs. Models 3 and 4 have log dependent variables while explanatory variables are in levels. Models 5 and 6 are linear in levels.

Models 2, 4, and 6 remove the dummy variable for metro area 2. Using the Phillips-Ouliaris tests, only in models 1 and 2 can we conclude that the variables are cointegrated. For the other models, the test $p$ value is larger than 0.15 so we cannot reject that the variables of the models are not cointegrated. Our discussion will therefore focus on models 1 and 2.

Models 1 and 2 fit the data quite well with adjusted-R squares of 0.90 . The coefficient for the price ratio is negative, as expected. An increase of $1 \%$ in the price ratio decreases consumption share by $5.6 \%$. The coefficient for the number of fuel stations per square mile is positive as expected with a $1 \%$ increase in the number of fuel stations per square mile increasing consumption share by $1 \%$. This means that newly installed E85 fuel stations tap into a pool of motorists who otherwise would not fuel with E85, and that these motorists have the same attitude toward E85 as those who were already served by an E85 fuel station. The estimated coefficient on the dummy variable for metro area 2 is small and is most likely not statistically significant in model 1 . Because the variables are cointegrated, we cannot make statistical inference using a t-statistic. But the standard error being 16 times larger than the value of the estimated coefficient for the dummy for metro area 2 provides evidence that there is no variable other than the price ratio and the concentration of E85 pumps per square mile explains the difference in consumption share in metro areas 1 and 2.

\footnotetext{
${ }^{\ddagger \ddagger}$ A table of results for these tests is available from the authors by request.
} 
The bottom of Table 1 shows predicted market shares for price ratios of $0.85,0.776,0.70$, and 0.60. The shares are predicted given data observed at the end of 2014 for metro area 1. At a price ratio of 0.776 , the cost per mile of E85 equals the cost per mile of E10 and models 1 and 2 predict consumption share of E85 around $12 \%$. This does not mean that only $12 \%$ of motorists are willing to pay at least the parity price for E85. The predicted market share encompasses both the willingness to pay and the cost to access E85. For lower price ratios of 0.70 and 0.65 , models 1 and 2 generate large increases in market shares. This reflects that the distribution of preference for E85 relative to E10 is such that a large number of motorists switch fuel when the price of E85 is discounted relative to the price of E10. At a price ratio of 0.65 , models 1 and 2 predict a consumption share of 0.32 .

Comparing the predicted consumption shares to the consumption shares plotted in Figure 2, it seems that the log-log models predict consumption shares that are in line with those empirically observed. At a price ratio of 0.65 , the cost per mile of driving with E85 is about $17 \%$ less than with E10. With this magnitude of cost savings, it seems that a consumption share is likely greater than the $15 \%$ maximum consumption share projected from models 5 and 6 . In appearance, the projected consumption shares in metro area 1 of more than $21 \%$ in models 1 and 2 for a price ratio 0.70 seem too large compared to the data points in Figure 2. However, most of the observations in Figure 2 for low price ratios were before the number of fuel stations offering E85 reached its maximum. Given that the number of E85 fuel stations is at its maximum at the end of 2014 , a $21 \%$ consumption share is realistic for a 0.70 price ratio.

\section{Extrapolation of Results to the National Level}

To extrapolate our findings from our two metropolitan areas, we identified all metropolitan statistical areas in the United States as defined by the Census Bureau. ${ }^{\S \S}$ The rationale for choosing these metro

\footnotetext{
${ }^{\S}$ The core-based statistical area (CBSA) is defined as the "counties or equivalent entities associated with at least one core (urbanized area or urban cluster) of at least 10,000 population, plus adjacent counties having a high degree of social and economic integration with the core as measured through commuting ties with the counties
} 
areas is that our empirical estimates are for relatively densely populated areas and therefore it is more justified to extrapolate consumption in metro areas where population density is similar to our sample. Travel distance and access to fuel stations is likely similar among urban areas so we expect motorists across urban areas to behave consistently. This assumption is important because the regression estimates in Table 1 are affected by the distance traveled to access E85. Figure 3 shows a map of the zip codes selected. It includes major US cities and suburbs. Because the Census Bureau defines metro areas by counties, there are some metro areas that cover very large areas with low density population, in particular in Arizona. An alternative to the metropolitan areas defined by the Census Bureau would be to use zip code areas where the population density is similar to our two metro areas. This alternative approach yields similar results. The densely populated areas are those with the most E85 fuel stations and with the greatest concentration of FFVs. In the selected metropolitan areas there are a total of 9.6 million FFVs and a total of 1,528 publically accessible fuel stations offering E85.

We can derive the demand for E85 in metro areas using the regression outputs presented in Table 1. We project the consumption in each metropolitan area based on regression model 2 because it is not conditioned on the metropolitan area and it is a cointegration relationship. We calculate the total consumption by multiplying the predicted consumption share in each metropolitan area by 910 gallons, which is the consumption of E85 that yields the same miles driven as the consumption of 683 gallons of E0. Then we sum-up the consumption at each station to find the aggregate for the entire United States. Note that additional consumption of ethanol from the 8 to 9 million FFVs located outside US metro areas is not included in the consumption estimates we present below.

The USDA introduced in 2015 the Biofuel Infrastructure Partnership to increase the availability of E85 (USDA 2015). The program provided $\$ 100$ million in matching funds for the installation of up to 
5,000 pumps offering higher ethanol blends in 21 states. The measure the potential impacts of the program, we estimate the demand for E85 with between zero and 5,000 new pumps.

Figure 4 shows the estimated demand for E85 in the selected metropolitan areas given investment to distribute $\mathrm{E} 85$ to add zero, 1,000, 2,500 or 5,000 E85 pumps. In panel A, fuel pumps are added strategically to maximize E85 consumption. Stations are added iteratively according to the number of FFVs per station per metropolitan area. That is, a station is first added to the metropolitan area with the largest number of FFVs per station. The value for the number of FFVs per station is then recalculated and another station is added to the metropolitan area with the largest number of FFVs per square mile. This process is repeated until the 1,000, 2,500, or 5,000 E85 fuel stations are added. Retailers are likely not to install new E85 pumps uniquely on the basis of the number of FFVs and hence the demand curves we report in panel A are too optimistic. In panel B we offer an alternative where new E85 fuel stations are allocated randomly across metro areas. This allocation is more conservative and perhaps closer to how new E85 stations would be allocated given all the factors that can motivate the addition of new fuel stations.

Comparing panels $A$ and $B$, the predicted consumption is much lower when new E85 fuel stations are randomly allocated across metropolitan areas. At cost-per-mile parity, consumption of E85 is nearly 285 million gallons when no new stations are added. If 5,000 new E85 pumps are added strategically, consumption grows to 1.2 billion gallons of E85. But, if the stations are randomly allocated, consumption increases to only 675 million gallons of E85. With no new E85 pumps, the consumption of 1 billion gallons of E85 requires a price ratio of about 0.62 . If stations are added according to the number of FFVs per station, the consumption of 1 billion gallons of E85 requires a price ratio of 0.67 with 1,000 new E85 pumps added, a price ratio about 0.73 if 2,500 new stations are added, and a price ratio 0.80 if 5,000 new stations are added. With the location of new E85 stations randomly assigned, the price ratios to induce consumption of 1 billion gallons of E85 are much lower. Consumption of 1 billion 
gallons of E85 requires a price ratio of 0.65 with 1,000 new E85 pumps added, a price ratio about 0.68 if 2,500 new stations are added, and a price ratio 0.71 if 5,000 new stations are added.

The demand curves in Figure 4 are of course not representative of the demand for E85 in the entire United States because they consider only metropolitan areas. However, these demand curves show the potential for significant increases in consumption of E85 when it is discounted with respect to E10, particularly with new strategically located E85 stations.

\section{Conclusion and Policy Implications}

The decision by EPA to propose to reduce RFS ethanol mandates in 2014, 2015, and 2016 on the basis that consumer demand for ethanol is insufficient to meet a 15-billion-gallon target was based on EPA's belief that too few owners of FFVs will switch to E85 if is it attractively priced to save them money and/or that there is insufficient incentive in the market-based RIN trading system to facilitate expansion in the number of stations that sell E85. Our analysis provides EPA and others with improved knowledge of the proportion of urban FFV owners that will buy E85 at different price points. Our results indicate that a significant proportion of FFV owners in metro areas will buy E85 if it is priced to save them money on a cost-per-mile basis. In one metro area that has one E85 station for every 2,070 FFVs, the market share of E85 exceeded 15\% when E85 saved flex motorists a small amount of money. Using these new data to estimate a functional relationship between the relative price of E85 and market share, we predict a market share of $23 \%$ when the price of E85 relative to E10 drops to 0.70 , which generates savings of $10 \%$ for those drivers who switch. This same function shows that increasing the number of E85 stations significantly increases E85 sales. If 5,000 new E85 stations were located where US FFVs are located, then almost 2 billion gallons of E85 could be consumed in all U.S. metro areas. This level of E85 consumption would push U.S. ethanol consumption well beyond 15 billion gallons. Additionally, large amounts of ethanol would also be sold in rural areas. 
Our finding that owners of FFVs like to save money on their fuel purchases is not too surprising. EPA recognizes that the way to get lower E85 prices is to have a high RIN price. RIN prices increase the more difficult biofuel targets can be met. Because the price of RINs represents a tax on gasoline production that is sold domestically, a lower RIN price lowers the tax on gasoline producers. Thus, gasoline producers have an incentive to increase the supply of RINs to lower their price. One way of increasing the supply of RINs is to expand the consumption of E85. EPA set up the RIN trading system to create the incentive to invest in the infrastructure that is needed to expand the consumption of biofuels which, in turn, lowers RIN price.

The RIN price for corn ethanol on August 12, 2016 was approximately 80 cents. With both wholesale gasoline and ethanol prices trading at $\$ 1.40$, an 80 cent RIN price, if completely passed through to wholesale E85 prices, implies an E85 price of $\$ 0.80$ per gallon. Adding a fixed wholesale-toretail markup of $\$ 0.75$ per gallon to both E85 and E10 wholesale prices results in E85 costing a bit less than E10 on a cost-per-mile basis. Our analysis indicates that combining this level of relative prices with the expected 5,000 new E85 pumps being installed will result in sales of between 675 million and 1.25 billion gallons of E85 in metro areas, which translates to between 500 and 900 billion gallons of ethanol consumption. This range depends on whether the 5,000 new stations are located randomly or strategically. With 14 billion gallons of ethanol consumed as E10, and additional E85 consumption in rural areas, total ethanol consumption at current prices is likely high enough to meet a 15 billion gallon blending target. Higher blending targets could be achieved with higher RIN prices. This level of consumption however will only be achieved if current RIN prices are passed through to wholesalers and retailers. If pass through is incomplete, then consumption levels will fall short of 15 billion gallons without a large increase in RIN prices. The degree of RIN pass through is the subject of ongoing research efforts. 


\section{References}

Aguilar, F. X., Zhen Cai, P. Mohebalian, and W. Thompson. 2015. "Exploring the drivers' side of the "blend wall": US consumer preferences for ethanol blend fuels." Energy Economics 49: 217-226.

Alternative Fuels Data Center. 2015a. "Alternative Fueling Station Locator." Available at http://goo.gl/Bz7FXV.

Alternative Fuels Data Center. 2015b. "Average Annual Fuel Use of Major Vehicle Categories" Available at http://www.afdc.energy.gov/data/10308.

Alternative Fuels Data Center. 2016. "Alternative Fueling Station Locator." Available at http://goo.gl/Bz7FXV.

Anderson, S.T. and Sallee, J.M., 2011. Using loopholes to reveal the marginal cost of regulation: The case of fuel-economy standards. The American Economic Review, 101, 1375-1409.

Anderson, S.T. 2012. "The demand for ethanol as a gasoline substitute." Journal of Environmental Economics and Management 63: 151-168.

Babcock, B.A. 2013. “Ethanol without Subsidies: An Oxymoron or the New Reality?” American Journal of Agricultural Economics 95: 1317-1324.

Bento, A.M., R. Klotz, and J. Landry. 2015. “Are There Carbon Savings from U.S. Biofuel Policies? The Critical Importance of Accounting for Leakage in Land and Fuel Markets." Energy Journal 36(3): 75109.

Corts, K. S. 2010. "Building out alternative fuel retail infrastructure: Government fleet spillovers in E85." Journal of Environmental Economics and Management 59(3): 219-234.

de Gorter, H., D. Drabik and D.R. Just. 2013. "Policy Implications of High RIN Prices and the 'Blend Wall'." Biofuels 4: 359-361.

Drabik, D., De Gorter, H., Just, D.R. and Timilsina, G.R., 2015. The Economics of Brazil's Ethanol-Sugar Markets, Mandates, and Tax Exemptions. American Journal of Agricultural Economics, 97(5): 14331450. 
de Gorter, H. and Drabik, D., 2015. The Distinct Economic Effects of the Ethanol Blend Wall, RIN Prices and Ethanol Price Premium due to the RFS. Available at: http://publications.dyson.cornell.edu/research/researchpdf/wp/2015/Cornell-Dyson-wp1511.pdf. EIA. 2015. "Short-Term Energy Outlook: May 2015." Available at: http://www.eia.gov/forecasts/steo/archives/may15.pdf.

EPA. 2015a. “Renewable Fuel Standard Program: Standards for 2014, 2015, and 2016 and Biomassbased Diesel Volume for 2017." Available at: http://www.regulations.gov/\#!documentDetail;D=EPA FRDOC 0001-17472.

EPA. 2015b “Renewable Fuel Standard Program: Standards for 2014, 2015, and 2016 and Biomass-based Diesel Volume for 2017." Available at: https://www.gpo.gov/fdsys/pkg/FR-2015-12-14/pdf/201530893.pdf.

Knittel, C. K., B. S. Meiselman and J. H. Stock. 2015. "The Pass-Through of RIN Prices to Wholesale and Retail Fuels under the Renewable Fuel Standard." NBER working paper 21343. Available at: http://www.nber.org/papers/w21343.

Lin, C.-Y.C., Prince, L., 2013. "Gasoline price volatility and the elasticity of demand for gasoline." Energy Economics 38: 111-117.

Liu, C. and Greene, D., 2014. Consumer Choice of E85 Denatured Ethanol Fuel Blend: Price Sensitivity and Cost of Limited Fuel Availability. Transportation Research Record: Journal of the Transportation Research Board, 2454: 20-27.

Petrolia, D. R., S. Bhattacharjee, D. Hudson, and C. W. Herndon. 2010. "Do Americans want ethanol? A comparative contingent-valuation study of willingness to pay for E-10 and E-85." Energy Economics 32: 121-128.

Pouliot, S. and B.A. Babcock. 2014. "The Demand for E85: Geographical Location and Retail Capacity Constraints." Energy Economics 45:134-143. 
Pouliot, S., and B.A. Babcock. 2016. "Compliance Path and Impact of Ethanol Mandates on Retail Fuel Market in the Short Run." American Journal of Agricultural Economics, forthcoming.

Roberts, M. J., and W. Schlenker. "Identifying Supply and Demand Elasticities of Agricultural

Commodities: Implications for the US Ethanol Mandate." The American Economic Review 103, no. 6 (2013): 2265-2295.

Tyner, W. E., and D. Viteri. 2010. "Policy Update: Implications of blending limits on the US ethanol and biofuels markets." Biofuels 1(2): 251-253.

Tyner, W. E. 2010. "The integration of energy and agricultural markets. "Agricultural Economics 41(1): 193-201.

US Census Bureau. 2014. "2014 U.S. Gazeteer Files." Available at http://www.census.gov/econ/cbp/index.html.

US Census Bureau, 2015. “County Business Patterns." Available at http://www.census.gov/geo/maps-data/data/gazetteer2014.html.

USDA. 2015. "Fact Sheet: USDA Invests in Clean Energy Economy, Supporting U.S. Producers and Seeking to Double Number of Higher Blend Renewable Fuel Pumps Available to Consumers." Available at: http://www.usda.gov/wps/portal/usda/usdahome?contentid=2015/05/0157.xml.

Whistance, J., W. Thompson, and P. Westhoff. 2014. "Are RIN Prices High Enough for E85 Expansion." FAPRI-MU Bulletin 01-15. Available at:

http://www.fapri.missouri.edu/wp-content/uploads/2015/02/FAPRI MU Bulletin 01 15.pdf. 


\section{Figures}

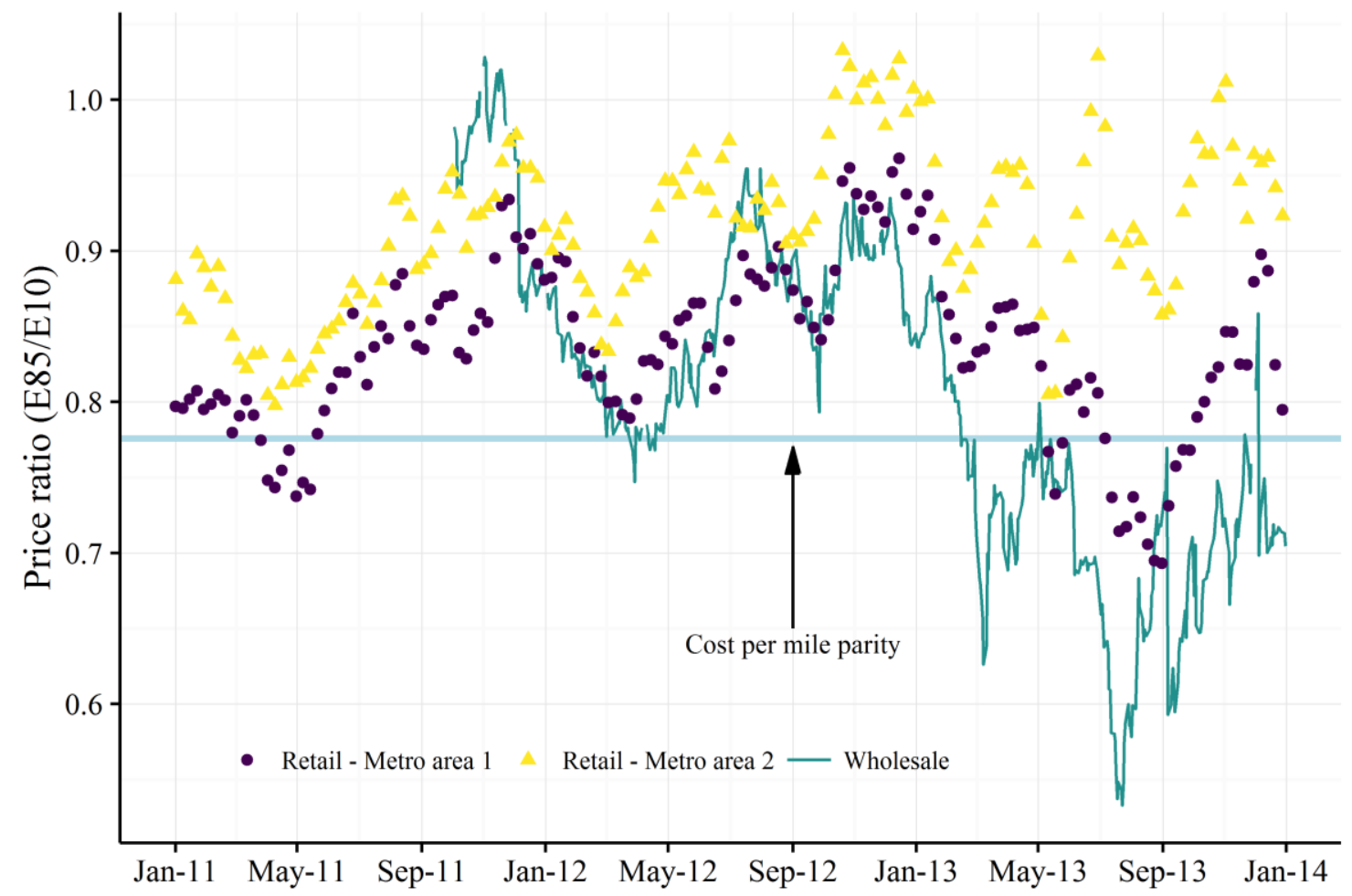

Note: The wholesale price ratio series begin in October 2011 because historical ethanol futures price data are not available prior to that date.

Figure 1. Ratio of the wholesale and retail prices of E85 and E10 


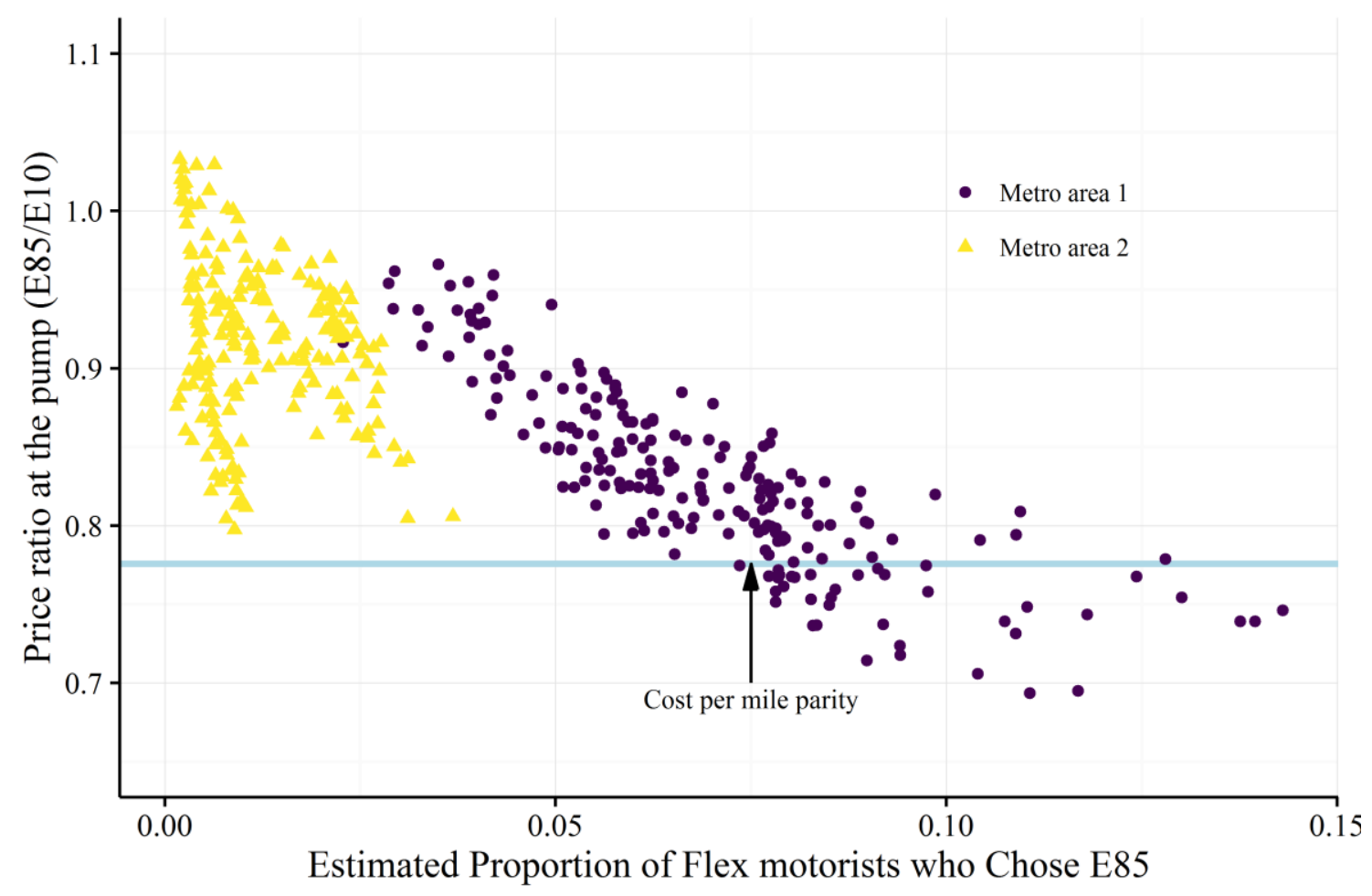

Figure 2. Market Penetration of E85 in Two Metro Areas 


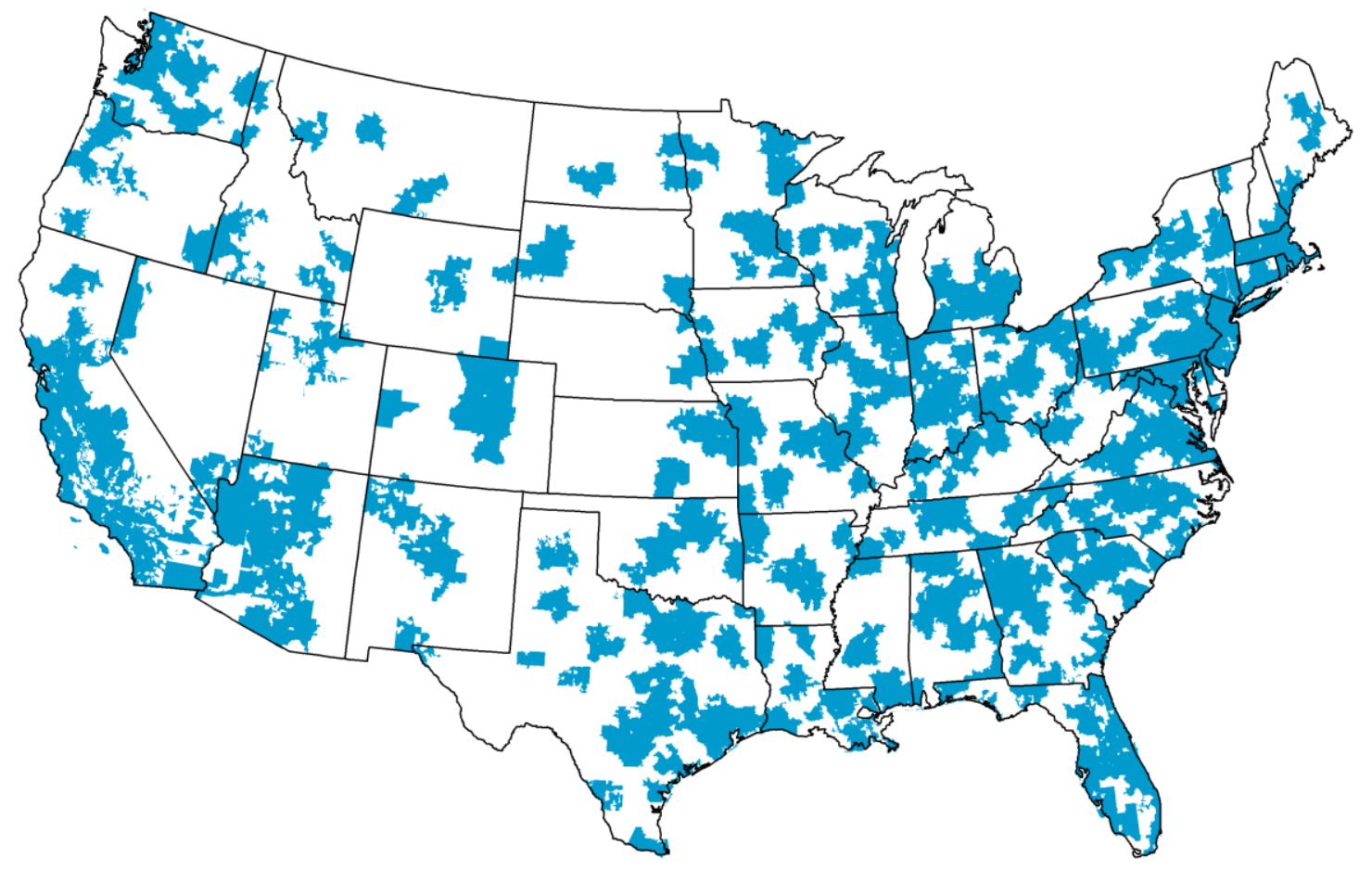

Figure 3. Selected metropolitan areas 


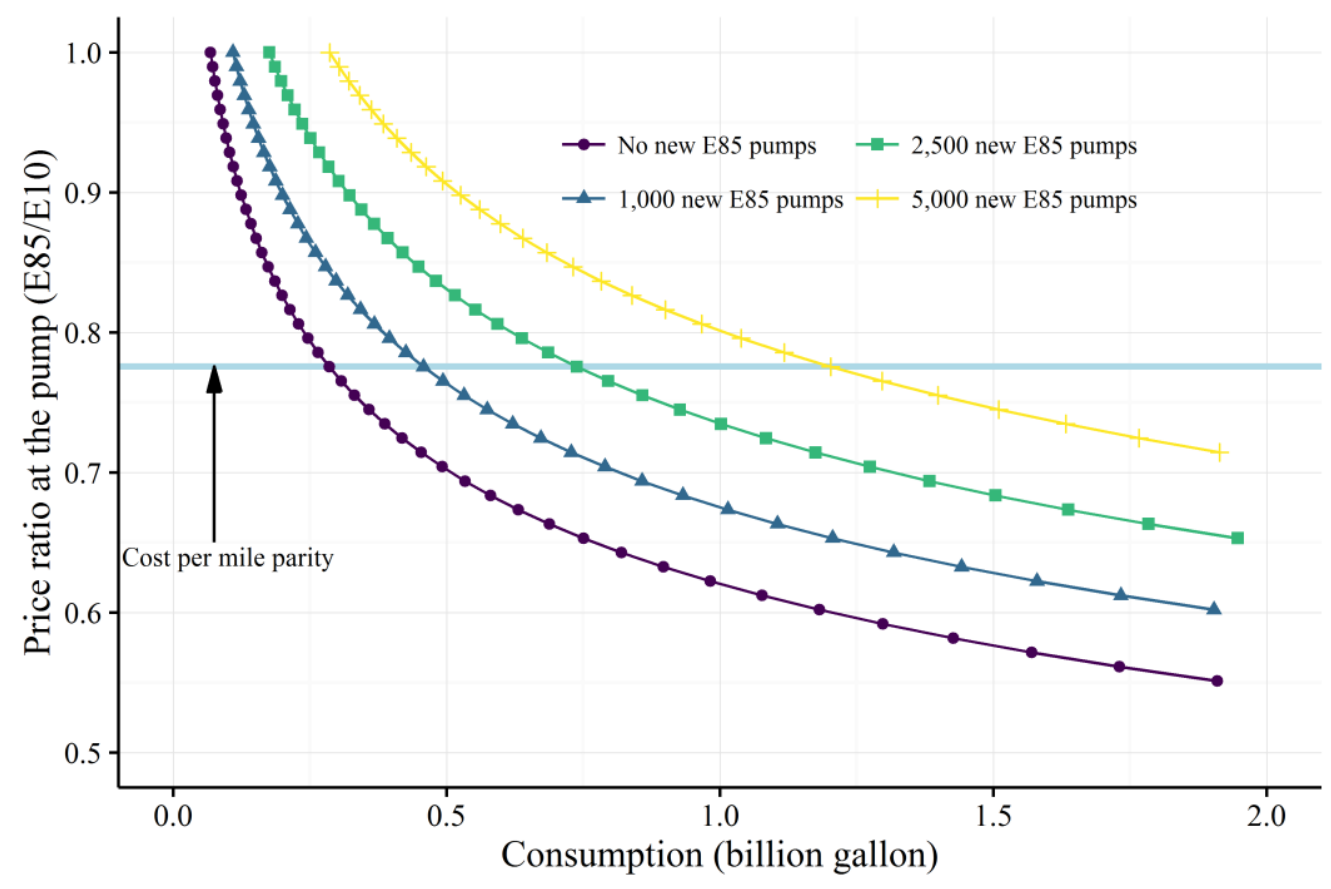

A) Strategic location of new E85 stations based on the number flex fuel vehicles per station

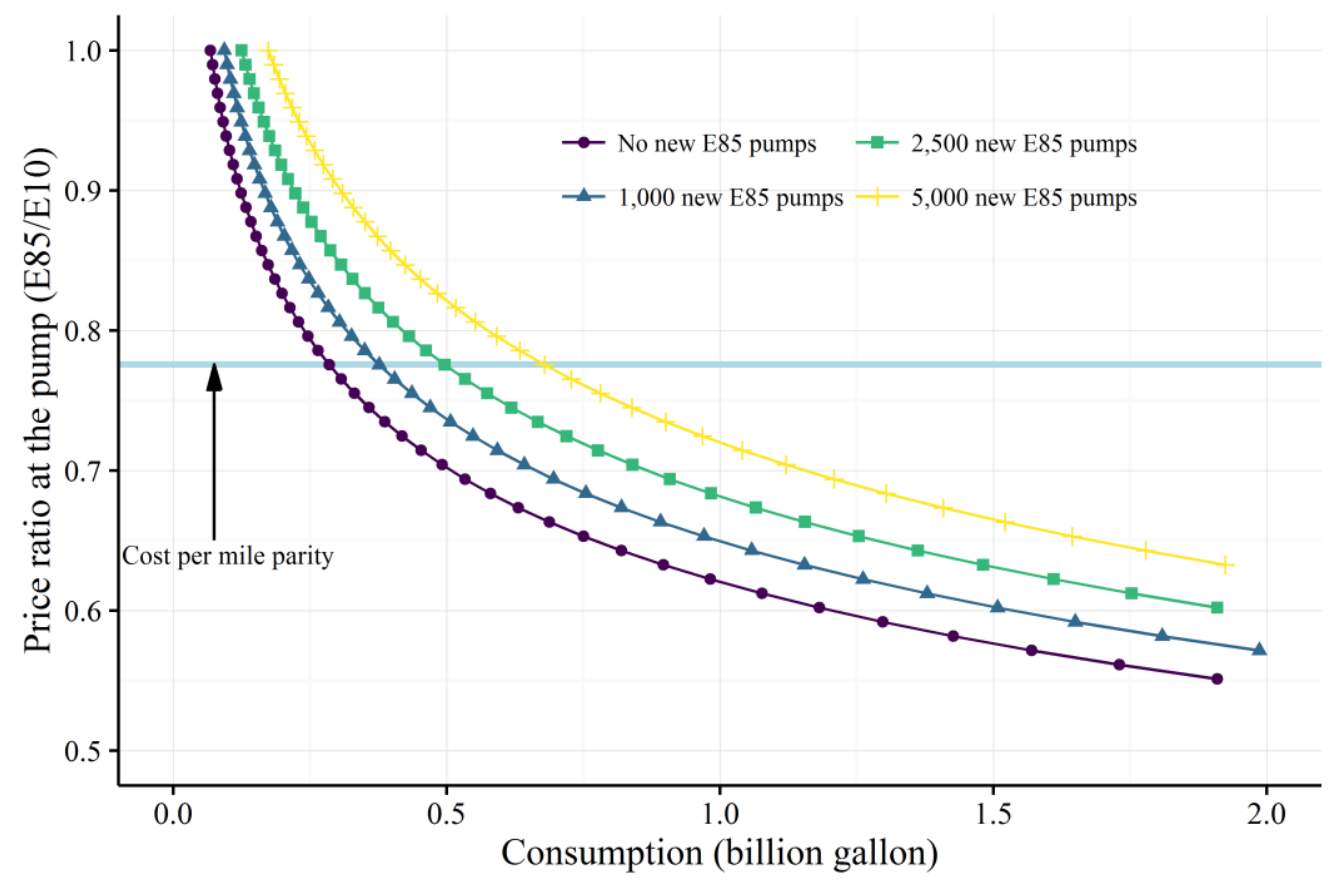

B) Random location of new E85 stations

Figure 4. Estimated consumption of E85 in selected metropolitan areas 


\section{Tables}

Table 1: Regressions of Consumption Share of E85 and Predicted Consumption Share

\begin{tabular}{|c|c|c|c|c|c|c|}
\hline & \multicolumn{2}{|c|}{$\log -\log$} & \multicolumn{2}{|c|}{ linear-log } & \multicolumn{2}{|c|}{ linear-linear } \\
\hline & Model 1 & Model 2 & Model 3 & Model 4 & Model 5 & Model 6 \\
\hline \multirow[t]{2}{*}{ Intercept } & -0.780 & -0.776 & -0.138 & -0.175 & 0.199 & 0.192 \\
\hline & $(0.135)$ & (0.109) & $(0.334)$ & $(0.333)$ & (0.009) & $(0.010)$ \\
\hline \multirow[t]{2}{*}{ Price ratio } & -5.642 & -5.651 & -5.309 & -5.516 & -0.173 & -0.209 \\
\hline & $(0.272)$ & $(0.226)$ & $(0.384)$ & $(0.351)$ & $(0.011)$ & $(0.011)$ \\
\hline \multirow[t]{2}{*}{ Station per square mile } & 1.010 & 1.012 & 35.493 & 39.37 & 0.273 & 0.954 \\
\hline & $(0.046)$ & $(0.025)$ & $(3.267)$ & $(1.354)$ & $(0.092)$ & $(0.041)$ \\
\hline \multirow[t]{2}{*}{ Metro area 2} & -0.005 & & -0.178 & & -0.031 & \\
\hline & $(0.083)$ & & $(0.137)$ & & $(0.004)$ & \\
\hline $\operatorname{Adj}-R^{2}$ & 0.902 & 0.903 & 0.838 & 0.838 & 0.846 & 0.822 \\
\hline PO (p-value) & 0.069 & 0.028 & $>0.15$ & $>0.15$ & $>0.15$ & $>0.15$ \\
\hline \multicolumn{7}{|c|}{ Predicted market share in metro area 1} \\
\hline Price ratio $=0.850$ & 0.071 & 0.071 & 0.090 & 0.093 & 0.069 & 0.075 \\
\hline Price ratio $=0.776$ & 0.118 & 0.118 & 0.133 & 0.14 & 0.082 & 0.09 \\
\hline Price ratio $=0.700$ & 0.211 & 0.211 & 0.199 & 0.212 & 0.095 & 0.106 \\
\hline Price ratio $=0.650$ & 0.320 & 0.321 & 0.260 & 0.28 & 0.104 & 0.116 \\
\hline
\end{tabular}

Note: The values in parentheses are standard errors. There are 209 observations in the dataset.

Significance is not indicated because coefficients do not follow a standard distribution. PO is the Philips-

Ouliaris cointegration with the null-hypothesis that the variables of the model are not cointegrated. 